Rätselhafter Leichenfund

\title{
Unfallopfer landet im Kofferraum
}

Ein Autofahrer prallt in der Nacht auf ein Hindernis. Benommen inspiziert er sein Fahrzeug und findet einen toten im Kofferraum. Über diesen ungewöhnlichen Verkehrsunfall berichtete Dr. Ronny Bayer vom Institut für Rechtsmedizin in Leipzig.

Ein Mann war mitten in der Nacht auf der Autobahn mit $120 \mathrm{~km} / \mathrm{h}$ unterwegs. Plötzlich prallte sein Auto an ein nicht erkennbares Hindernis. Der Fahrer bremste stark, blieb unverletzt und konnte aussteigen. Noch vom Schock benommen lief er zur Rückseite des Wagens und öffnete die Heckklappe. Das automatische Einschaltlicht beleuchtete eine überraschende Szenerie: Im Kofferraum lag ein teilweise entkleideter, älterer Mann in widernatürlicher Position. Der Kopf war fast rechtwinklig zum Körper rotiert, und auch die Beine waren stark verrenkt. Sofort rief der Fahrer die Polizei.

Als die Polizisten sich vor Ort umgesehen hatten, führte sie die ungewöhnliche Auffindesituation zunächst zu dem Verdacht, dass der Fahrer in einen illegalen Leichentransport verwickelt war. Aber warum sollte er sich selbst verraten? Bei der weiteren Betrachtung des Unfallwagens fielen dann starke Deformationen des Fahrzeugs an der Front, aber auch am Dach und am Heck auf. Mit einem einfachen frontalen Aufprall waren diese Beschädigungen nicht zu erklären. Die Polizei veranlasste eine Sektion des Leichnams sowie ein unfallanalytisches Gutachten.

\section{Frakturen von Kopf bis Fuß}

Bei diesen Untersuchungen zeigten sich komplexe Frakturen an beiden Beinen, am Becken, den Rippen sowie am 11. und 12. Brust- und am 2. Halswirbelkörper, die zusammen das Bild einer starken stumpfen Gewalteinwirkung zeichneten. Das verlängerte Rückenmark des Toten war komplett durchgerissen. Am
Kopf zeigten sich glattrandige Hautdurchtrennungen. Zum Zeitpunkt der Gewalteinwirkung musste der Mann bekleidet gewesen sein, da Löcher, Schnitte und Stoffeinschmelzungen an Hose und Jacke festgestellt wurden. Die Lunge war perforiert. Nebenbefundlich wurden ein Hydrocephalus internus und eine Hirnatrophie festgestellt.

Der Unfallwagen zeigte sich in einem ebenso zerstörten Zustand. Auf der rechten Seite waren Licht, Stoßstange und Kotflügel deutlich deformiert. Die Motorhaube war beschädigt und die Windschutzscheibe rechts zersplittert. Auf dem Dach fand man Wischspuren. Die Heckscheibe war komplett zerstört und die C-Säule verformt. Technische Störungen fanden sich am Auto nicht.

\section{Wie kam der Mann in den Kofferraum?}

Da der Verdacht des Leichentransports mit der kaputten Heckscheibe nicht unbedingt vereinbar war, lag die Vermutung nage, dass der Mann im Kofferraum auch das Aufprallhindernis gewesen war. Doch wie war er danach ins Innere des Autos gelangt?

Die Gutachter kombinierten die Verletzungen des Opfers und die Deformationen am Unfallwagen und gingen von folgendem Unfallhergang aus: Das Opfer befand sich auf der Autobahn, als ihn das Auto von hinten mit der rechten Seite erwischte. Durch den Anprall schlug er mit der linken Hüfte auf die Motorhaube auf und überschlug sich, sodass sein Kopf und sein Oberkörper mit der Windschutzscheibe kollidierten. Der Körper überschlug sich weiter nach hinten und wurde hochgeschleudert. Dabei kam er mit dem Dach des Autos in Kontakt und hinterließ dort die später festgestelltenSpuren.

Es war erst ein Augenblick vergangen. Auto und Unfallopfer bewegten sich nun beide in Fahrtrichtung, das Auto etwas schneller. Als der Fahrer auf den Aufprall reagierte und auf die Bremse trat, war der Körper des Mannes gerade nach hinten über das Auto hinweg geflogen. Durch die abrupte Bremsung des Autos schlug er nun in die Heckscheibe ein und landete im Kofferraum. Dort fand ihn der Autofahrer. Durch den Flug und den Aufprall war er teilentkleidet und die höchst ungewöhnliche, "gefaltete“ Endlage gebracht worden. Der Fahrer hatte in seiner Aufregung und wegen der Dunkelheit zunächst gar nicht bemerkt, dass auch die Heckscheibe des Autos zerstört war.

\section{Im Alleingang nicht zu lösen}

Und das Opfer? Die Polizei ermittelte, dass der Tote Bewohner eines nahen Pflegeheims war. Er war seit dem Vorabend vermisst worden und litt unter beginnender Demenz.

Fazit: Eine interdisziplinäre Zusammenarbeit aus Rechtsmedizinern und unfallanalytischen Sachverständigen gewährleistet auch bei höchst ungewöhnlichen Unfallabläufen eine gute Unfallrekonstruktion. Dafür sollten sie frühzeitig hinzugezogen werden.

(Viktoria Ganß)

Bayer R et al. Poster "Eine Leiche im Kofferraum. 95. Jahrestagung der Deutschen Gesellschaft für Rechtsmedizin; Heidelberg, 30. August 2016 